\title{
Epistaxis in a Pediatric Outpatient Clinic: Could It be an Alarming Sign?
}

\author{
Mohsen Saleh ElAlfy ${ }^{1}$ Azaa Abdel Gawad Tantawy ${ }^{1}$ Badr Eldin Mostafa Badr Eldin ${ }^{2}$ \\ Mohamed Amin Mekawy ${ }^{3}$ Yasmeen Abd elAziz Mohammad ${ }^{1} \quad$ Fatma Soliman Elsayed Ebeid ${ }^{1}$ () \\ ${ }^{1}$ Department of Pediatrics, Faculty of Medicine, Ain-Shams University, \\ Cairo, Egypt \\ ${ }^{2}$ Department of Ear, Nose and Throat Surgery, Faculty of Medicine, \\ Ain-Shams University, Cairo, Egypt \\ Address for correspondence Fatma Soliman Elsayed Ebeid, MD, \\ MRCPCH, Pediatrics Department, Faculty of Medicine, Ain Shams \\ University, 2 Lotfy Elsayed Street, Cairo, Egypt 11566
}

${ }^{3}$ Department of Clinical Pathology, Faculty of Medicine, Ain-Shams

University, Cairo, Egypt

Int Arch Otorhinolaryngol 2022;26(2):e183-e190.

\begin{abstract}
Introduction Epistaxis is a common presentation among children.

Objective To investigate the suitability of a simple tool of assessment for patients with epistaxis that could guide in subgrouping those with possible bleeding tendencies who may need further assessment.

Methods Children who presented to a tertiary outpatient clinic with epistaxis of an unknown cause were recruited. They underwent thorough clinical assessment and answered the pediatric bleeding questionnaire and the epistaxis severity score. All patients underwent complete blood count as well as coagulation profile, and confirmatory diagnostic tests were performed as needed.

Results Among the 30,043 patients who presented to the outpatient clinic over a year, 100 children had epistaxis, with an estimated annual frequency of 1 in 300 . A total of $84 \%$ of the patients were younger than 12, and nearly half of these were younger than 6 years. Seventy-six patients had recurrent epistaxis, and 12 had systemic comorbidities. A significant higher percentage of patients presented with epistaxis in the hot months of the year. A total of $90 \%$ of the patients presented anterior bleeding, and the majority were treated with nasal compression only. Forty-three patients presented with epistaxis only; 37 of them were diagnosed as idiopathic epistaxis, and 6 had local causes. Fifty-seven patients presented with other bleeding manifestations, 47 of whom had a definite bleeding disorder and the other 10 had undiagnosed bleeding tendency. Those with other bleeding manifestations showed a higher frequency of positive family history of epistaxis; of being referred from a primary care physician; of having alarming low platelet count, and of

Keywords

- epistaxis

- children

- outpatient clinic

- bleeding disorder presenting less seasonal variability. A bleeding score $\geq 2$ showed significant value in suspecting an underlying systemic pathology as a cause of epistaxis.

Conclusion The pediatric bleeding questionnaire is a useful and simple tool in the identification of pediatric patients who need further diagnostic testing to detect any underlying bleeding tendency.
\end{abstract}

received

February 26, 2020

accepted

November 24, 2020

published online

June 3, 2021
DOI https://doi.org/ 10.1055/s-0041-1726040. ISSN 1809-9777.

\footnotetext{
(C) 2021. Fundação Otorrinolaringologia. All rights reserved.

This is an open access article published by Thieme under the terms of the Creative Commons Attribution-NonDerivative-NonCommercial-License, permitting copying and reproduction so long as the original work is given appropriate credit. Contents may not be used for commercial purposes, or adapted, remixed, transformed or built upon. (https://creativecommons.org/ licenses/by-nc-nd/4.0/)

Thieme Revinter Publicações Ltda., Rua do Matoso 170, Rio de Janeiro, RJ, CEP 20270-135, Brazil
} 


\section{Introduction}

Epistaxis is defined as acute bleeding from the nostril, nasal cavity, nasopharynx, ${ }^{1,2}$ or the paranasal sinuses, ${ }^{3}$ and it is a common problem among children, representing a prevalent emergency in otolaryngology. Most nosebleeds are benign, self-limited, and rarely life-threatening. ${ }^{4}$ It is crucial to diagnose the cause of the bleeding, whether it is local or secondary to inherited systemic coagulopathy, as this strongly affects the management and might require the presence of a pediatric hematologist in the management team, alongside the otolaryngologist. ${ }^{5}$

There is limited data regarding the prevalence of nosebleeds in children because most episodes are self-limited and, thus, not reported. When medical attention is needed, it is usually because of either the recurrent or severe nature of the problem. ${ }^{6}$ It was estimated previously that $60 \%$ of the general population will have an episode of epistaxis at some point in their lives. ${ }^{7}$ On the other hand, epistaxis is rare in children younger than 2 years of age ( $\sim 1$ per 10,000) and should raise prompt consideration of trauma (intentional or unintentional), serious illness (e.g., thrombocytopenia), ${ }^{8}$ or child abuse. ${ }^{9}$

Although most of the severe cases of inherited bleeding disorders will be diagnosed in an early stage of life, moderate and mild cases may not be detected. ${ }^{10}$ We believe that in our region, the prevalence of bleeding disorders is higher than the international prevalence, due to a higher rate of marriages among family relatives; however, the exact rate is unknown. The current cross-sectional study aims to measure the frequency and etiology of epistaxis as a presenting symptom among children who visited a tertiary pediatric outpatient clinic and to determine the frequency of secondary epistaxis due to bleeding tendency using the available simple assessment tools (bleeding score and epistaxis severity score [ESS]). Our hypothesis was that the use of a simple tool of assessment could guide in subgrouping those patients with epistaxis who might need further assessment. This could increase the diagnosis rate of inherited bleeding disorders in children presenting with epistaxis and, eventually, improve the care given to the affected children.

\section{Patients and Methods}

This is a cross-sectional study in which the subjects were recruited from the outpatient clinic of the Pediatrics Hospital of the Ain Shams University over 6 working days (from Saturday to Thursday), in the working hours from 9 Am until 12 PM, over a 1-year study period starting in December 2016.

The participants were pediatric patients (younger than 18 years) who presented to the outpatient clinic with epistaxis of unknown cause. Patients older than 18 years or having epistaxis due to evident surgical or traumatic cause or because of an evident medical cause, such as an inherited bleeding disorder, liver-cell failure, or because of administration of aspirin or warfarin, were excluded.

An informed consent was obtained from the subjects and/or their legal guardians before participation. The procedures applied in this study were approved by the Ethical Committee of Human Experimentation of the Ain Shams University and are in accordance with the Helsinki Declaration of 1975 with Federal wide assurance (FWA) number: 000017585.

All the recruited patients underwent thorough clinical assessment with special emphasis on the demographic data, history of trauma or any chronic illness, history of current infection or inflammation, history of other bleeding manifestations, and family history of epistaxis, bleeding tendency or blood product transfusion. An ear, nose, and throat (ENT) examination was performed by an assigned trained physician using anterior rhinoscopy.

The following two simple questionnaires were completed:

1. The pediatric bleeding questionnaire $(\mathrm{PBQ}):^{11}$ The online version of this questionnaire can be accessed in the "Supporting Information" part of the article's citation (https://onlinelibrary.wiley.com/doi/full/10.1111/j.15387836.2010.03975.x/),

2. Epistaxis severity score (ESS): Self-reported questionnaire on the frequency of epistaxis, duration and amount of attack, proportion of child's life that the nosebleed has been recurrent, and whether the nosebleed is unilateral or bilateral. Each component was scored 0,1 , or 2 . The sum of the scores of all components was stratified as mild, if it was $0 \geq 6$, or severe if $7 \geq 10$. $^{12}$

The patients were classified into two groups according to whether their bleeding was only restricted to the nose (group A: Patients with probable local bleeding) or associated with other bleeding manifestations (group B: Patients with probable systemic bleeding).

Peripheral blood samples were collected under complete aseptic conditions for the evaluation of complete blood count (CBC), prothrombin time (PT), and partial thromboplastin time (PTT). Two milliliters of fresh peripheral blood samples were collected on potassium ethylene diamine tetra-acetic acid (K2-EDTA) (1.2 mg mL - 1) as an anticoagulant to perform CBC on Sysmex XT-1800i (Sysmex, Kobe, Japan). For PT and PTT, two milliliters of fresh peripheral blood samples were obtained on sodium citrated vacutainer (1-part citrated sodium (0.11 $\mathrm{mol} / \mathrm{L}$ ) with nine parts venous blood, (platelet poor plasma) was collected by centrifugation at 3,000 $\times \mathrm{g}$ for 15 minutes and was performed on a Stago autoanalyzer Dubai (UAE).

Confirmatory investigations were performed in patients who showed abnormalities in their basic bleeding profile (CBC, PT, and PTT) as well as in those with normal basic bleeding profile yet a bleeding score exceeding $\geq 2$, which may indicate an underlying bleeding tendency. Confirmatory investigation was performed according to abnormality detected and included platelet functions analysis, coagulation factor assay, and Von Willebrand factor (VWF) antigen and cofactor activity assessment.

\section{Statistical Analysis}

The data were collected, revised, coded and entered to the IBM SPSS Statistics for Windows, Version 23.0 (IBM Corp., Armonk, NY, USA). Quantitative variables were described in the form of mean and standard deviation or median and interquartile range (IQR; 75th and 25th percentiles). Qualitative variables 
were described as number and percentages. To compare parametric quantitative variables between two groups, the Student $t$-test was applied. For comparison of non-parametric quantitative variables between two groups, the MannWhitney test was used. Qualitative variables were compared using the chi-squared $\left(\mathrm{x}^{2}\right)$ test or Fischer exact test when frequencies were below five. Receiver operating characteristic (ROC) curves were used to assess the best cut-off point with sensitivity, specificity, positive, and negative predictive value (PPV and NPV) and area under the curve (AUC). The confidence interval was set to $95 \%$, and the margin of error accepted was set to $5 \%$. So, the $p$-value significance was set as follows: $P$-value $>0.05$ was considered non-significant (NS), and $P$-value $<0.05$ was considered significant in all analyses.

\section{Results}

A total of 30,043 patients presented to the outpatient clinic of the Ain Shams University Hospital through the 1-year study period; 106 patients presented with epistaxis, and 6 of them were lost to follow-up or had incomplete data; only 100 patients with complete data were enrolled in the study, with an estimated frequency of epistaxis of around 1 in 300 annually. Out of the 100 recruited patients, 53 were female and 47 were male, and all of them were older than 2 and younger than 18 years old, with a mean of $7.89 \pm 3.89$ years. Most of the recruited patients were younger than 12 , and nearly half of them were younger than 6 years old; $48 \%$ were aged 2 to 6 years, $36 \%$ were 6 to 12 , and $16 \%$ were 12 to 18 years. In our study, 29 cases had consanguineous parents and 71 cases did not, and nearly half of the recruited patients (54\%) had positive family history of epistaxis. Seventy-six patients had recurrent attacks of epistaxis, and 24 patients had a single attack.

Seventeen out of 100 recruited patients had comorbidities. Five of them had local comorbidities: three patients had allergic rhinitis, one had paranasal sinusitis, and one had concha bullosa. The other 12 patients had systemic comorbidities, mainly diabetes mellitus (4 patients) and gastrointestinal disease ( 3 patients). There was a significantly higher percentage of patients who presented with epistaxis than those who presented with other complaints in the warm months of June, July, August, and September, and a lower percentage in the spring months of February and March, as illustrated in - Fig. (1). Most of the patients (90\%) presented with anterior bleeding; 10 had undetermined site of bleeding, and none had posterior bleeding. One hundred patients presented with epistaxis; most of them (96\%) were treated with only nasal compression as a procedure, while 4 had anterior pack and 2 underwent cauterization.

Forty-three patients presented with epistaxis only (group A: patients with suspected local bleeding); 37 of them had normal ENT assessment and normal initial hematological assessment (CBC, PT, and PTT), as illustrated in - Table 1. They were diagnosed with idiopathic epistaxis; 6 patients had local ENT causes ( 4 had allergic rhinitis and 2 had infections).

Fifty-seven patients presented with other bleeding manifestations (group B: patients with suspected systemic bleeding). The most frequent associated bleeding manifestations were cutaneous bleeding; petechiae (32 patients) and ecchymosis (25 patients), followed by bleeding gum (18 patients) and menorrhagia (14 patients). The least frequent associations were bleeding per rectum ( 4 patients) and bleeding after tooth extraction (3 patients). The pediatric bleeding score and ESS of

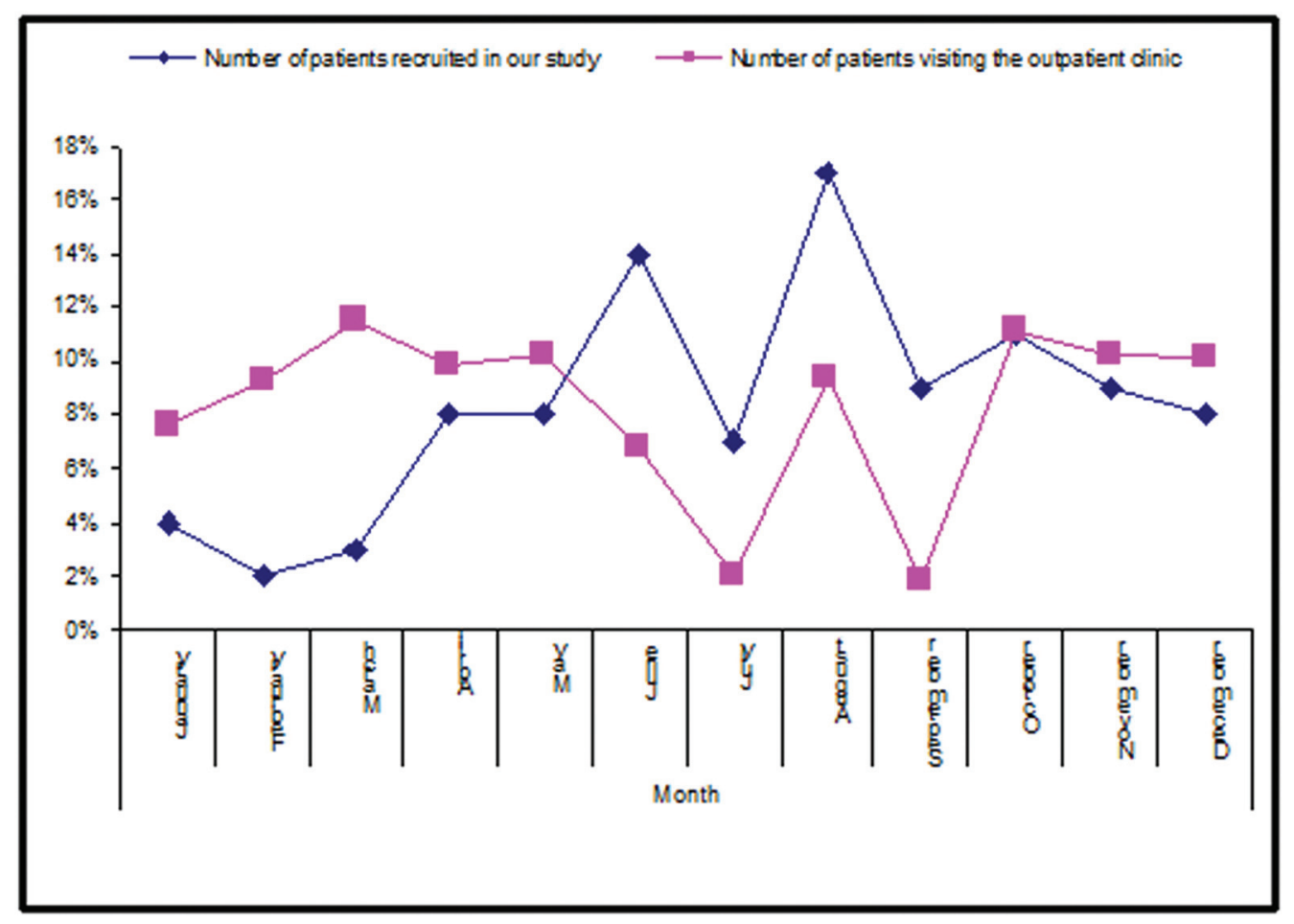

Fig. 1 The percentage of patients visiting the outpatient clinical of Ain Shams University Pediatric hospital in compare to the percentage of patients recruited in our study (those presented with epistaxis) monthly. 
Table 1 Comparison between local and systemic cause of epistaxis in regards to the studied parameters

\begin{tabular}{|c|c|c|c|c|c|}
\hline & & $\begin{array}{l}\text { Group B: Patients with } \\
\text { probably systemic bleeding } \\
N=57\end{array}$ & $\begin{array}{l}\text { Group A: Patients with } \\
\text { probably local bleeding } \\
N=43\end{array}$ & Test value & $P$-value \\
\hline \multirow[t]{2}{*}{ Sex; N (\%) } & Female & $30(52.6 \%)$ & $23(53.5 \%)$ & \multirow[t]{2}{*}{$0.007^{*}$} & \multirow[t]{2}{*}{0.932} \\
\hline & Male & $27(47.4 \%)$ & $20(46.5 \%)$ & & \\
\hline \multirow[t]{3}{*}{ Age; N (\%) } & $2-6$ years & $16(37.2 \%)$ & $32(56.1 \%)$ & \multirow[t]{3}{*}{$3.763^{*}$} & \multirow[t]{3}{*}{0.152} \\
\hline & $>6-12$ years & $19(44.2 \%)$ & $16(28.1 \%)$ & & \\
\hline & $>12-18$ years & $8(18.6 \%)$ & $9(15.8 \%)$ & & \\
\hline \multicolumn{2}{|c|}{ Consanguinity; N (\%) } & $19(33.3 \%)$ & $10(23.3 \%)$ & $1.209^{*}$ & 0.272 \\
\hline \multicolumn{2}{|c|}{ Family history; N (\%) } & $25(43.9 \%)$ & $29(67.4 \%)$ & $5.487^{*}$ & 0.019 \\
\hline \multicolumn{2}{|c|}{ Recurrent; N (\%) } & $42(73.7 \%)$ & $34(79.1 \%)$ & $0.390^{*}$ & 0.532 \\
\hline \multicolumn{2}{|c|}{ Seasonal variation; N (\%) } & $18(31.6 \%)$ & $23(53.5 \%)$ & $4.864^{*}$ & 0.027 \\
\hline \multicolumn{2}{|c|}{ Referred patients; N (\%) } & $27(47.4 \%)$ & $4(9.3 \%)$ & $16.604^{*}$ & 0.000 \\
\hline \multicolumn{2}{|c|}{$\begin{array}{l}\text { Total leucocytic count }\left(10^{3} / \mathrm{uL}\right) \\
\text { mean } \pm \text { SD (range) }\end{array}$} & $\begin{array}{l}7.75 \pm 2.19 \\
(4-12.1)\end{array}$ & $\begin{array}{l}7.71 \pm 2.66 \\
(4-16.7)\end{array}$ & $0.087^{\bullet}$ & 0.931 \\
\hline \multicolumn{2}{|c|}{$\begin{array}{l}\text { Hemoglobin }(\mathrm{gm} / \mathrm{dl}) ; \text { mean } \pm \\
\text { SD (range) }\end{array}$} & ${ }_{6-14}^{11.19} \pm 1.56$ & $\underset{9-13}{11.14 \pm 0.81}$ & $0.212^{\circ}$ & 0.833 \\
\hline \multicolumn{2}{|c|}{$\begin{array}{l}\text { Platelets }\left(10^{3} / \mathrm{uL}\right) ; \text { mean } \pm \text { SD } \\
\text { (range) }\end{array}$} & $\begin{array}{l}202.68 \pm 140.13 \\
(4-500)\end{array}$ & $\begin{array}{l}258.72 \pm 85.00 \\
(127-455)\end{array}$ & $-2.319^{\circ}$ & 0.023 \\
\hline \multicolumn{2}{|c|}{$\begin{array}{l}\text { Pediatric bleeding score; medi- } \\
\text { an (IQR) }\end{array}$} & $\begin{array}{l}6(4-9) \\
0-20\end{array}$ & $\begin{array}{l}1(0-1) \\
0-7\end{array}$ & -7.458 & 0.000 \\
\hline \multicolumn{2}{|c|}{$\begin{array}{l}\text { Epistaxis severity score; median } \\
\text { (IQR) }\end{array}$} & $\begin{array}{l}4(2-6) \\
0-10\end{array}$ & $\begin{array}{l}2(0-5) \\
0-8\end{array}$ & -2.098 & 0.036 \\
\hline
\end{tabular}

${ }^{*}$ Chi-squared test

- Independent $t$-test.

Qualitative data are presented as number and percentages, in which the chi-squared test was used for comparisons. Quantitative data are presented as mean with standard deviations, when parametric, in which the independent $t$-test was used, and as median with interquartile ranges (IQRs), when nonparametric, in which the Mann-Whitney tests was used.

this group are illustrated in - Table 1. Patients with suspected systemic bleeding and/or those who had abnormal initial hemogram and coagulation profile performed further laboratory tests to reach a final diagnosis. The VWF antigen assay and VW cofactor activity as well as platelet function tests with adenosine diphosphate and Ristocetin were performed for 32 patients; consequently, 12 patients had platelet function defect (PFD) and 10 patients had Von Willebrand disease (VWD). Only 6 patients needed coagulation factor assay and revealed that 1 patient had factor- 7 deficiency, 1 patient had hemophilia $\mathrm{A}$ and one patient had hemophilia B. Only eight patients underwent bone marrow (BM) examination; they had bipancytopenia or associated hepatosplenomegaly and generalized lymphadenopathy; four had abnormal BM aspiration (BMA); one case had myelodysplasia, and three cases had aplastic anemia. Four patients had normal BMA with peripheral platelet destruction and were diagnosed as idiopathic thrombocytopenic purpura (ITP) .

Consequently, 47 patients had a definite bleeding disorder and 10 had undiagnosed bleeding tendency; 16 had immune mediated disease (14 patients had ITP and 2 patients had autoimmune diseases [antiphospholipid antibody syndrome and systemic lupus], 25 had inherited defect [12 patients had PFD, 10 patients had VWD, one had factor 7 deficiency, one had hemophilia $\mathrm{A}$ and one had hemophilia B]and 6 had other diseases (one case had myelodysplasia and 3 cases had aplastic anemia, one patient had DIC, one patient had poststreptococcal glomerulonephritis and hypertension). Out Of them 43 patients are now regularly following up at pediatric hematology clinic as shown in - Fig. (2).

We compared patients presenting with epistaxis only (local bleeding) with those presenting with other types of bleeding to identify the predictors of bleeding tendency in patients presenting with epistaxis, as illustrated in - Table 1 . There was a statistically significantly higher number of patients with a positive family history of epistaxis in those with suspected systemic cause. Low platelets count significantly alerts for probably a systemic cause of epistaxis. The presence of seasonal variation of epistaxis was statistically significant in favor of the local cause of epistaxis. There was a statistically higher number of patients with suspected systemic cause of epistaxis, and these were referred from a primary care physician to our outpatient clinic.

The ROC curve analysis showed that a bleeding score of 2 or more was of a high statistical significance in the detection of an underlying systemic cause of bleeding, as it gave sensitivity of $85.96 \%$ and specificity of $95.35 \%$ with the area under the curve (AUC) being 0.932, PPV of 96.1, and NPV) of 83.7. Whereas ESS of 2 or more showed statistically significant value in the detection of an underlying systemic 
Between $22^{\text {nd }}$ of December 2015 and $22^{\text {nd }}$ of December 2016 30043 patients presented to the Outpatient clinic

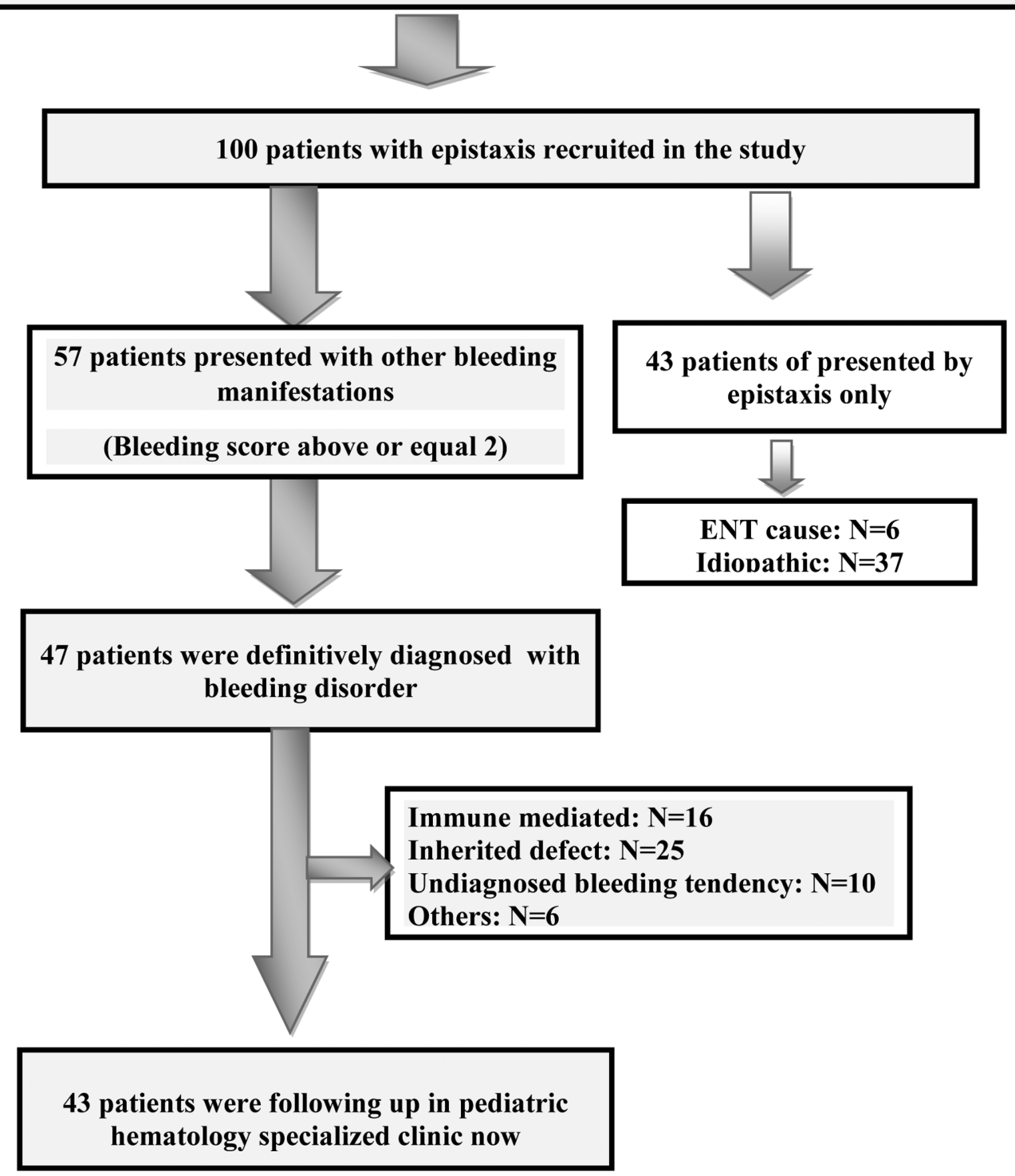

Fig. 2 Schematic approach of screened and recruited patients.

cause of epistaxis, as it gave sensitivity of $66.67 \%$ and specificity of $58.14 \%$ with the AUC being 0.621 , PPV of 67.9, and NPV of 56.8. A boxplot (-Fig. 3) showed that bleeding score and ESS were statistically significantly higher in those with possible systemic underlying causes of epistaxis than those with possible local causes.

\section{Discussion}

Epistaxis is one of the main complaints in ENT outpatient clinics $^{13,14}$; it is considered the second most common cause of emergency admission following sore throat. ${ }^{13}$ Our estimated frequency of epistaxis in a pediatric outpatient clinic setting, with exclusion of traumatic causes, was 1 in 300 . This frequency was not far from a 10-year study, which found that epistaxis accounts for $\sim 4$ in 1,000 pediatric emergency department visits among children in the United States. ${ }^{7}$

None of our recruited patients was younger than 2 years, which is in agreement with the fact that epistaxis rarely occurs in children under 2 years of age. ${ }^{15,16}$ The majority of our recruited patients were younger than 12 and adolescents had the lowest frequency, which agrees with a Brazilian study that reported that up to $60 \%$ of children experience one episode of epistaxis prior to the age of $10 .{ }^{17}$ Furthermore, Haddad ${ }^{16}$ reported that the commonest age for its occurrence is 3 to 8 years old, yet, this is a little bit lower in the ages of 10 to 15 , and, finally, the incidence of epistaxis decreases after puberty.

The gender distribution in our study showed nearly equal frequency in both genders; this agrees with the results obtained in a Turkish study, ${ }^{18}$ which showed that $52.5 \%$ 

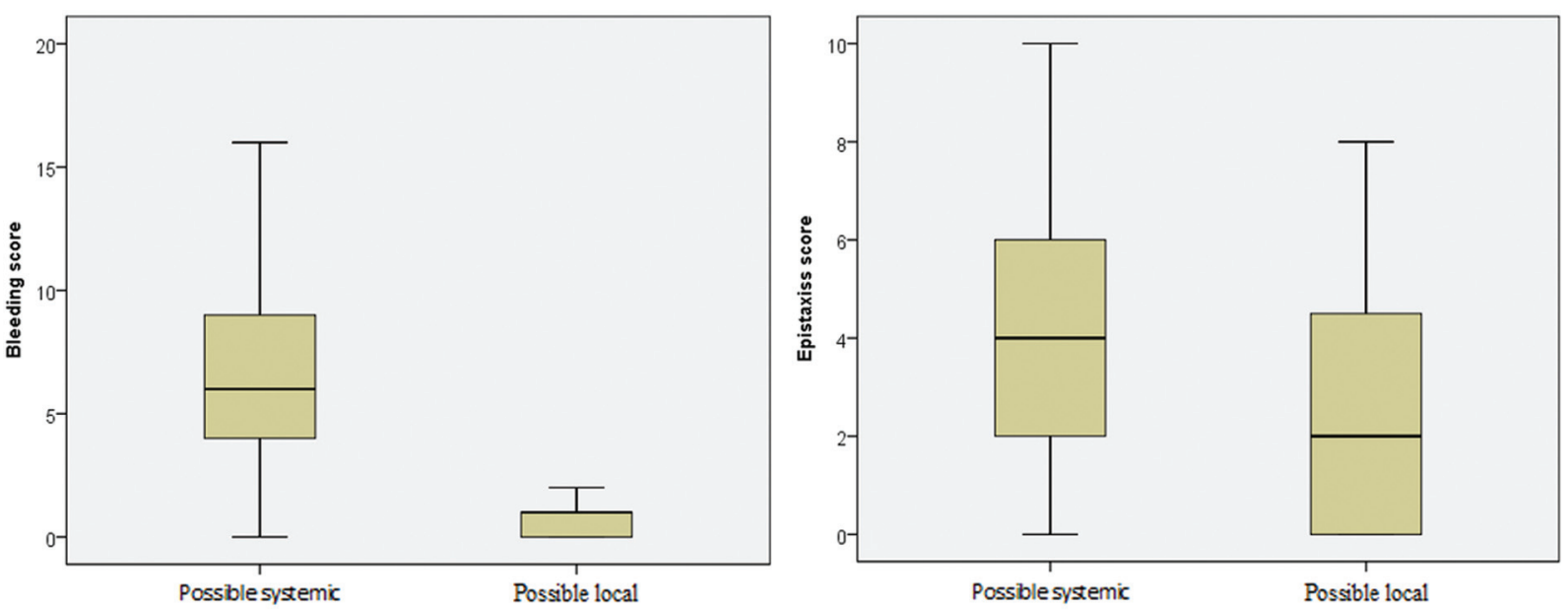

Fig. 3 The values of bleeding score (2A) and epistaxis severity score (2B) in differentiated between local and systemic underlying cause of epistaxis.

patients were male and $47.5 \%$ were female. However, it contrasts with the findings of Hassan et al., ${ }^{19}$ who conducted a study in Bangladesh in which the majority (68\%) of his patients was male, with the male to female ratio being $2: 1$; the higher percentage of males was explained by the higher incidence of traumatic cause in the enrolled patients. In family history analysis, $54 \%$ of the patients had positive family history, and these had a higher incidence of suspected systemic cause of epistaxis than those with negative family history. This could be explained by the high rate of consanguineous marriages (29\%) among the studied patients and the relatively high rate of rare factor deficiencies due to consanguinity of the parents. ${ }^{18}$

Seasonal variations in the occurrence of epistaxis have been noted, but studies regarding the association of epistaxis and climatic events have yielded inconsistent results. ${ }^{17,20-22}$ We reported significant monthly variation in recruiting the patients, as there were a significantly higher number of patients presenting with epistaxis in the warm months of the year and a lower number during the spring; this variation may be attributed to seasonal variation. Our results were similar to those of a Turkish study, ${ }^{23}$ which found that epistaxis occurrence was positively related to mean temperature. This finding contradicts the results obtained in a study conducted in the United States in which epistaxis occurred more often in the fall and winter, when temperatures are lower. ${ }^{24-26}$

Epistaxis causes can be broadly classified into either local or systemic causes. ${ }^{27}$ The local causes may be in the form of inflammation and infection within the nares, nasal cavity, nasopharynx, and sinuses, dry air exposure, ${ }^{28}$ local irritation by chemicals, ${ }^{29}$ vascular anomalies, ${ }^{30}$ local digital manipulation-the most common cause $-{ }^{31}$ and erosion of the nasal mucosa in the Little region of the nasal septum, ${ }^{32}$ which is the most common cause in adolescents. But, in most of cases, the etiology is not determined. ${ }^{33}$ Allergic rhinitis has been implicated as a cause of epistaxis episodes in children, potentially due to direct irritation as a response to associated inflammation, congestion, and rhinorrhea. ${ }^{34}$ In our study, allergic rhinitis was the most common local comorbidity in children with epistaxis.
Almost all types of bleeding disorders, both congenital and acquired, ${ }^{35}$ may present with epistaxis. ${ }^{36,37}$ In children with severe bleeding disorders, the bleeding history is usually clear; however, children with mild-to-moderate bleeding disorders may present with recurrent epistaxis, that is a common complaint in children, ${ }^{38}$ and often causes significant anxiety in patients and their family members. ${ }^{2}$ Both before and during the diagnosis, these patients may go through considerable clinical problems and cause diagnostic and therapeutic challenges and an economic burden. ${ }^{39,40}$ Screening for bleeding disorders in children with controllable episodes may often be overlooked, ${ }^{41}$ so referral to a specialized hematologist is of value in diagnosing and sparing these patients the risk of future unexplained bleeding without a clear diagnosis and management protocol. ${ }^{42}$

Nearly half of the studied patients were at last diagnosed as having a bleeding disorder. These results are very close to those of a retrospective Turkish study ${ }^{18}$ of 26,737 patients of an ambulatory pediatrics division, between 31 October 2011 and 31 October 2012. Ninety-nine patients presented with bleeding symptoms; 36 of these presented with epistaxis, and nearly $1 / 3$ of them (36.4\%) were diagnosed with a bleeding disorder, after exclusion of all patients with immune thrombocytopenia. The high incidence of VWD in both studies (12 patients in Turkish study, ${ }^{18} 10$ patients in our study) could be explained by the fact that both studies were conducted at a tertiary hospital and in Middle Eastern countries, where consanguineous marriages are common. ${ }^{43}$ Furthermore, Egyptian studies conducted at the Pediatric Hematology clinic of the Ain Shams University revealed that epistaxis represented $15 \%$ of the presenting symptoms of inherited coagulation disorders ${ }^{43}$ and were reported in $10 \%$ of pediatric ITP. ${ }^{44}$ Another Egyptian study showed that $47.6 \%$ of patients with recurrent epistaxis had bleeding disorders ${ }^{45}$ and that bruising and epistaxis were the main symptoms in all children with VWD. ${ }^{46}$

Epistaxis can be classified into recurrent and single-episode epistaxis. Recurrent epistaxis is a common occurrence in children, estimated to affect up to $9 \%$ of the pediatric population $^{42}$ and represents a concern for both child and parents. Recurrent epistaxis is even of more important, as it 
rises our suspicion of an underlying bleeding disorder. In patients with recurrent epistaxis, the rate of detecting a bleeding disorder is 5.5 to $33 \%{ }^{31,47}$ Because emergency providers may often be the first line of evaluation of a patient with recurrent epistaxis, their understanding of the symptoms and laboratory assessments leading to a diagnosis of bleeding tendencies is, therefore, critical to identifying and properly managing these disorders. ${ }^{31,47}$ Among patients manifesting with recurrent epistaxis, the rate of detection of a bleeding disorder had a very wide range of 5.5 to $33 \%{ }^{31,47}$ Most of our studied patients had recurrent attacks of epistaxis (76\%); of them, 42 (55\%) patients had systemic cause and 34 had local cause.

The treatment of epistaxis requires a systematic and methodical approach, and options vary according to the cause, location, and severity of the hemorrhage. ${ }^{48}$ The majority of our pediatric patients had anterior bleeding, which is consistent with the data available in the literature, ${ }^{19,31,49}$ and most them (96\%) were treated with nasal compression only, which is also consistent with another study in which the majority (88\%) of the patients were left alone with medical advice and observed. ${ }^{19}$

In general, clinical judgment with consideration of the patient's clinical presentation, symptoms, age, family history, and degree of bleeding guide the outpatient evaluation of pediatric epistaxis, and, eventually, most of the epistaxis cases require no laboratory testing. ${ }^{50}$ Unfortunately, the published data do not clearly define which pediatric epistaxis cases require further laboratory investigation for bleeding disorders. ${ }^{47}$ Although patients who present with these symptoms may have underlying bleeding disorders, initial tests for bleeding etiology may yield normal results. Therefore, other factors should be considered which may predispose epistaxis in patients and may affect hemostasis. ${ }^{47}$

The first reported application of a bleeding questionnaire was by Rodeghiero et al. ${ }^{11}$ Since then, several questionnaires have been evaluated and validated for diagnosing bleeding disorders in children presenting to the office with bleeding complaints. ${ }^{51}$ Our hypothesis was that the use of simple tool of assessment could guide in subgrouping those patients with epistaxis who in need for further assessment. We found that a PBQ of 2 or more had high significance in detecting an underlying systemic cause of bleeding; it gave sensitivity of $85.9 \%$ and specificity of 95.35 . The sensitivity, specificity, PPV and NPV of the PBQ were 83\%, 79\%, 0.14, and 0.99, respectively, in an earlier study. ${ }^{10}$ Consequently, we recommend the use of the PDQ to predict the need to be referred to a pediatric hematologist for assessment. Furthermore, we found that the referrals from the primary care physician (PCP) showed higher incidence of having a systemic underlying cause of epistaxis. This may be due to the fact that non-hematologist PCPs are less likely to encounter individuals with suspected bleeding disorders, and this highlights the importance of good communication and referral of non-straightforward cases to a specialized hematologist to reach a diagnosis and receive a better management, which spares these patients from the risk of future unexplained bleeding without a clear diagnosis and management protocol.

\section{Conclusion}

The PDQ is a useful and simple tool in the identification of pediatric patients who present to pediatric outpatient clinics in need of further diagnostic testing to detect any underlying bleeding tendency.

Note

The present manuscript has not been submitted elsewhere nor previously published.

The corresponding author, on behalf of all authors, hereby states that all authors have contributed to the manuscript in significant ways, reviewed and agreed upon the manuscript content.

\section{Conflict of Interests}

The authors have no conflict of interests to declare.

\section{References}

1 Schechter M, Stevens D. Epistaxis. In: T.K. McInerny H. M. Adam D. E. Campbell D. M. Kamat \& K. J. Kelleher.(Eds.) American Academy of Pediatrics Textbook of Pediatric Care. 20091461482-1488

2 Kodiya AM, Labaran AS, Musa E, Mohammed GM, Ahmad BM. Epistaxis in Kaduna, Nigeria: a review of 101 cases. Afr Health Sci 2012;12(04):479-482

3 McLarnon CM, Carrie S. Epistaxis. Surgery 2012;30:584-589

4 Moreau S, De Rugy MG, Babin E, Courtheoux P, Valdazo A. Supraselective embolization in intractable epistaxis: review of 45 cases. Laryngoscope 1998;108(06):887-888

5 Hussain G, Iqbal M, Shah SA, et al. Evaluation of aetiology and efficacy of management protocol of epistaxis. J Ayub Med Coll Abbottabad 2006;18(04):63-66

6 Pope LE, Hobbs CG. Epistaxis: an update on current management. Postgrad Med J 2005;81(955):309-314

7 Pallin DJ, Chng Y-M, McKay MP, Emond JA, Pelletier AJ, Camargo CA Jr. Epidemiology of epistaxis in US emergency departments, 1992 to 2001. Ann Emerg Med 2005;46(01):77-81

8 Paranjothy S, Fone D, Mann M, et al. The incidence and aetiology of epistaxis in infants: a population-based study. Arch Dis Child 2009;94(06):421-424

9 Weindling M. Nose bleeds, child protection and the difficulties faced by paediatricians. Acta Paediatr 2008;97(10):1318-1320

10 Bowman M, Riddel J, Rand ML, Tosetto A, Silva M, James PD. Evaluation of the diagnostic utility for von Willebrand disease of a pediatric bleeding questionnaire. J Thromb Haemost 2009;7(08):1418-1421

11 Rodeghiero F, Tosetto A, Abshire T, et al; ISTH/SSC joint VWF and Perinatal/Pediatric Hemostasis Subcommittees Working Group. ISTH/SSC bleeding assessment tool: a standardized questionnaire and a proposal for a new bleeding score for inherited bleeding disorders. J Thromb Haemost 2010;8(09):2063-2065

12 Katsanis E, Luke KH, Hsu E, Li M, Lillicrap D. Prevalence and significance of mild bleeding disorders in children with recurrent epistaxis. J Pediatr 1988;113(1 Pt 1):73-76

13 Barnes ML, Spielmann PM, White PS. Epistaxis: a contemporary evidence based approach. Otolaryngol Clin North Am 2012;45 (05):1005-1017

14 Andrade JSC, Albuquerque AM, Matos RC, Godofredo VR, Penido Nde OProfile of otorhinolaryngology emergency unit care in a high complexity public hospital. Rev Bras Otorrinolaringol (Engl Ed) $2013 ; 79(03): 312-316$

15 Boscardini L, Zanetta S, Ballardini G, et al. Epistaxis in children under the age of two: possible marker of abuse/neglect? A retrospective study in North-Eastern Piedmont hospitals. Minerva Pediatr 2013;65(01):71-75 
16 Haddad J. Acquired disorders of the nose. In: R. M. Kliegman B. F. Stanton N. S. Schor J. W. St. Geme III \& R. E. Behrman. (Eds.) Nelson Textbook of Pediatrics Philadelphia. 2011(19)1431-1433

17 Davies K, Batra K, Mehanna R, Keogh I. Pediatric epistaxis: epidemiology, management \& impact on quality of life. Int J Pediatr Otorhinolaryngol 2014;78(08):1294-1297

18 Yıldız İ, Ünüvar A, Kamer İ, et al. First-Step Results of Children Presenting with Bleeding Symptoms or Abnormal Coagulation Tests in an Outpatient Clinic. Turk J Haematol 2015;32(04):338-343

19 Hassan SI, Arsalan AJ, Begum D. Epistaxis in Children: Aetiology, Management and Outcome. Bangladesh J Child Health 2015;39 (02):73-76

20 Danielides V, Kontogiannis N, Bartzokas A, Lolis CJ, Skevas A. The influence of meteorological factors on the frequency of epistaxis. Clin Otolaryngol Allied Sci 2002;27(02):84-88

21 Bray D, Giddings CE, Monnery P, Eze N, Lo S, Toma AG. Epistaxis: are temperature and seasonal variations true factors in incidence? J Laryngol Otol 2005;119(09):724-726

22 Reddy VM, Judd O, Khalil H. Investigation of the influence of ambient temperature, atmospheric pressure and water vapour pressure on epistaxis admission rate. Rhinology 2010;48(03):348-351

23 Kemal O, Sen E. Does the weather really affect epistaxis? B-ENT 2014;10(03):199-202

24 Walker TWM, Macfarlane TV, McGarry GW. The epidemiology and chronobiology of epistaxis: an investigation of Scottish hospital admissions 1995-2004. Clin Otolaryngol 2007;32(05):361-365

25 Sowerby LJ, DeSerres JJ, Rudmik L, Wright ED. Role of season, temperature and humidity on the incidence of epistaxis in Alberta, Canada. J Otolaryngol Head Neck Surg 2014;43:10

26 Purkey MR, Seeskin Z, Chandra R. Seasonal variation and predictors of epistaxis. Laryngoscope 2014;124(09):2028-2033

27 Nash CM, Field SMB. Epidemiology of Epistaxis in a Canadian Emergency Department. Israeli J Emerg Med 2008;8:24-28

28 Whymark AD, Crampsey DP, Fraser L, Moore P, Williams C, Kubba H. Childhood epistaxis and nasal colonization with Staphylococcus aureus. Otolaryngol Head Neck Surg 2008;138(03):307-310

29 Zhai L, Zhao J, Xu B, Deng Y, Xu Z. Influence of indoor formaldehyde pollution on respiratory system health in the urban area of Shenyang, China. Afr Health Sci 2013;13(01):137-143

30 Record S. Practice guideline: epistaxis in children. J Pediatr Health Care 2015;29(05):484-488

31 Gifford TO, Orlandi RR. Epistaxis. Otolaryngol Clin North Am 2008;41(03):525-536, viii

32 Boscardini L, Zanetta S, Ballardini G, et al. Epistaxis in children under the age of two: possible marker of abuse/neglect? A retrospective study in North-Eastern Piedmont hospitals. Minerva Pediatr 2013;65(01):71-75

33 Smith J, Siddiq S, Dyer C, Rainsbury J, Kim D. Epistaxis in patients taking oral anticoagulant and antiplatelet medication: prospective cohort study. J Laryngol Otol 2011;125(01):38-42

34 Purkey MR, Seeskin Z, Chandra R. Seasonal variation and predictors of epistaxis. Laryngoscope 2014;124(09):2028-2033
35 Nichols A, Jassar P. Paediatric epistaxis: diagnosis and management. Int J Clin Pract 2013;67(08):702-705

36 Israels SJ, El-Ekiaby M, Quiroga T, Mezzano D. Inherited disorders of platelet function and challenges to diagnosis of mucocutaneous bleeding. Haemophilia 2010;16(Suppl 5):152-159

37 Nurden AT, Pillois X, Nurden P. Understanding the genetic basis of Glanzmann thrombasthenia: implications for treatment. Expert Rev Hematol 2012;5(05):487-503

38 Castaman G, Goodeve A, Eikenboom JEuropean Group on von Willebrand Disease. Principles of care for the diagnosis and treatment of von Willebrand disease. Haematologica 2013;98 (05):667-674

39 Mannucci PM, Duga S, Peyvandi F. Recessively inherited coagulation disorders. Blood 2004;104(05):1243-1252

40 Peyvandi F, Palla R, Menegatti M, et al; European Network of Rare Bleeding Disorders Group. Coagulation factor activity and clinical bleeding severity in rare bleeding disorders: results from the European Network of Rare Bleeding Disorders. J Thromb Haemost 2012;10(04):615-621

41 George JN, Caen JP, Nurden AT. Glanzmann's thrombasthenia: the spectrum of clinical disease. Blood 1990;75(07):1383-1395

42 McGarry GW. Recurrent epistaxis in children. BMJ Clin Evid 2013; 2013:0311

43 Mokhtar GM, Tantawy AA, Adly AA, Telbany MA, El Arab SE, Ismail M. A longitudinal prospective study of bleeding diathesis in Egyptian pediatric patients: single-center experience. Blood Coagul Fibrinolysis 2012;23(05):411-418

44 Elalfy MS. Three decades of experience in managing immune thrombocytopenia in children in Arab countries. Semin Hematol 2013;50(Suppl 1):S22-S25

45 Abdel Wahab MS, Fathy H, Ismail R, Mahmoud N. Recurrent epistaxis in children: When should we suspect coagulopathy? Egypt J Otolaryngol 2014;30:106-111

46 El-Bostany EA, Omer N, Salama EE, El-Ghoroury EA, Al-Jaouni SK. The spectrum of inherited bleeding disorders in pediatrics. Blood Coagul Fibrinolysis 2008;19(08):771-775

47 Sandoval C, Dong S, Visintainer P, Ozkaynak MF, Jayabose S. Clinical and laboratory features of 178 children with recurrent epistaxis. J Pediatr Hematol Oncol 2002;24(01):47-49

48 Bernius M, Perlin D. Pediatric ear, nose, and throat emergencies. Pediatr Clin North Am 2006;53(02):195-214

49 Mangussi-Gomes J, Enout MJ, Castro TC, de Andrade JS, Penido NO, Kosugi EM. Is the occurrence of spontaneous epistaxis related to climatic variables? A retrospective clinical, epidemiological and meteorological study. Acta Otolaryngol 2016;136(11):1184-1189

50 Patel N, Maddalozzo J, Billings KR. An update on management of pediatric epistaxis. Int J Pediatr Otorhinolaryngol 2014;78(08): 1400-1404

51 Mittal N, Naridze R, James P, Shott S, Valentino LA. Utility of a Paediatric Bleeding Questionnaire as a screening tool for von Willebrand disease in apparently healthy children. Haemophilia 2015;21(06):806-811 